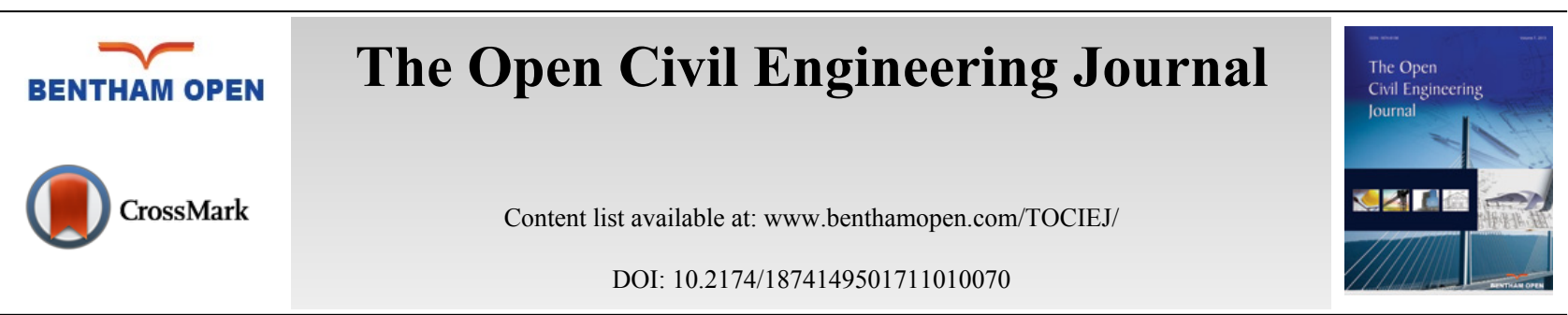

RESEARCH ARTICLE

\title{
Fuzzy Comprehensive Assessment Stability of Vegetated Slope with 3D Geomat Protection Using Cloud Model
}

\author{
Wang Guangyue*, Li Jiong, Ye Feifan and Sun Guorui \\ School of Civil Engineering, Shandong University, NO. 17923 Jingshi Road, Ji'nan, China
}

Received: July 23, 2016

Revised: October 23, 2016

Accepted: October 25, 2016

\begin{abstract}
Based on the analysis of the classification criteria from various factors, a comprehensive evaluation system of the erosion stability of the vegetated eco-slope protected by $3 \mathrm{D}$ geomat is established. To solve the problem of uncertainty in the slope erosion stability analysis and consider the feature of both of random and fuzziness, the theory of Cloud Model has been applied into comprehensive evaluation to realize the uncertainty conversion between the qualitative concept and the quantitative data. By constructing the qualitative rule generator, the specific score of the evaluation index is determined according to the uncertain reasoning. The weights of the evaluation indexes are determined with the help of the Analytic Hierarchy Process developed by Cloud Model (CM-AHP), and then the overall score of the comprehensive evaluation system is obtained. The results of engineering examples demonstrate the practicability and effectiveness of the assessment model, which provides a new way for the evaluation of the erosion stability of the vegetated eco-slope protected by the $3 \mathrm{D}$ geomat.
\end{abstract}

Keywords: 3D geomat, Comprehensive evaluation, Cloud model, Qualitative rule generator, Uncertainty, Vegetated slope.

\section{BACKGROUND}

In the construction of railway, highway, hydropower projects, the chances of slope excavation are always very high. The slope excavation may destroy the original vegetation and cause soil erosion, which may increase the degradation of the ecosystem. The traditional engineering slope protection technology, such as mortar or concrete protection, gunite, shotcrete and shotcrete-bolt slope protections, have made a great difference on slope protection. However, traditional slope protection technology are not environmentally friendly and the the cost of maintenance is very expensive. As a kind of composite ecological slope protection technology that combining 3D geomat and vegetation [1, 2], the vegetated eco-slope of 3D geomat protection technology is a combination of engineering and vegetation protection technology compared with the traditional slope protection technology. In the protection system, the 3D geomat is closely interwoven with the dense roots, thus making the root system integrated more uniformly and tightly, building a compactly complex system of the 3D geomat, the vegetation and the soil. The protection system works through the function of taproot anchoring, shallow root reinforcing, reducing pore water pressure of transpiration, intercepting rainfall and preventing slope runoff infiltration of vegetation, preventing the soil particles flowing through geomat. Besides, the honeycomb structure of 3D geomat can fix the planting soil on the slope, which provides essential soil and nutrients for the vegetation. The protection technology of vegetated eco-slope with 3D geomat has already been widely applied in the practical engineering because of the good effect for slope protection and ecological restoration.

However, there are some failure phenomena in practical engineering, such as the overall shear sliding along the slope of the protection system and partial erosion damage of the slope, making the ecological protection system ineffective. Especially at the initial formation stage of the protection system, rainfall may lead to poor stability of the protection system because the anti-rain-erosion function of the stems and leaves and the reinforcing and fastening soil

\footnotetext{
* Address correspondence to this author at the Shandong University, School of Civil Engineering, Shandong University, NO. 17923 Jingshi Road, Ji'nan, China; Tel: 8615610167735; E-mails: 963921014@qq.com,wgyue@sdu.edu.cn
} 
function of root system cannot work, since the vegetation has not been restored yet. Once there is any erosion damage in the protection system, it will not only lead to the failure of the ecological restoration, but also make the original slope expose to the surrounding environment again, resulting in the potential dangers such as landslide, debris flow and other geological disasters. Therefore, it is of great theoretical and practical significance to analyze and evaluate the erosion stability of the vegetated eco-slope protected by 3D geomat safely, reliably and effectively.

In order to analyze and evaluate the uncertainty problems and probabilistic engineering mechanics problems in slope engineering effectively, various numerical simulation and system analysis methods are introduced to the slope stability research, such as the principle of limit equilibrium [3], Fuzzy Comprehensive Evaluation [4], Grey System Theory [5], Clustering Analysis Method [6], Expert System [7], Neural Network [8], Monte Carlo simulation [9] and Genetic Algorithm [10]. Each of these methods has its own characteristics and can reflect the complexity of the analysis and assessment of the stability of the slope to a degree, which has great importance to the construction and designing of the engineering of the vegetated eco-slope protected with 3D geomat. However, in practice the assessment of the erosion stability of the vegetated eco-slope depends very much on the engineering survey and the experience of the experts, which will inevitably lead to fuzziness and randomness in the process of the evaluation and the tradition research method often neglects. Therefore, the result of the evaluation still need to be improved.

Cloud Model, put forward by Academician Li Deyi from China [11], is a model of conversion between the qualitative and the quantitative, which is based on Fuzzy Mathematics theory and Probability Statistics. By endowing the sample point the randomness, fuzziness and relevance of the concept, the uncertainty conversion of the qualitative language and the quantitative expression is realized, which overcomes the shortcomings of the traditional evaluation method in neglecting of the fuzziness and randomness. In this paper, the Cloud Model is introduced into the comprehensive evaluation of the erosion stability. Firstly, according to Cloud Model Qualitative Rule Generator based on the Cloud Model theory, the score of the evaluation index is obtained. Then the weight of each index is determined according to the Analytic Hierarchy Process improved by Cloud Model (AHP-CM). And finally the evaluation result of the whole system is obtained by weighted multiplication. Engineering examples demonstrate the method has very important academic significance and engineering application value which enriches and perfects the theoretical system of the vegetated eco-slope protection with $3 \mathrm{D}$ geomat.

\section{COMPREHENSIVE EVALUATION MODEL}

\subsection{Comprehensive Evaluation Index System}

To evaluate the erosion stability of the vegetated eco-slope protected with $3 \mathrm{D}$ geomat, the influencing factors of the erosion stability should be determined at first. Many scholars have made theoretical analysis and experimental exploration to determine the influencing factors of the erosion stability. As mentioned above, the protection system is made up of 3 parts: the slope, the 3D geomat and the vegetation. Therefore, the parameters of the three parts have been used to assess the erosion stability of the protection system.

For the slope, according to Rough Set theory [12] and finite element analysis of ABAQUS [13],the main factors that affect the erosion stability are bulk density of soil, cohesion, friction angle, slope angle and ratio of pore pressure. Besides, slope length and compactness are also critical factors affecting erosion stability of artificial slope.

To the 3D geomat, the mechanism of slope protection of the 3D geomat is encapsulating the surface soil and preventing the soil particles flowing. Once there emerges tensile failure on the 3D geomat, the encapsulating function of protection system will be ineffective. Therefore, the main influencing factors are thickness and tensile strength of the 3D geomat [14]. Besides, based on Safety Factor Method [15], anchor spacing is another important factor affecting the design of similar engineering.

In the protection system, the main function of the vegetation are slope erosion prevention, reinforcement effect of roots and ecological restoration. Therefore, according to these functions, the main influencing factors are rate of vegetation coverage, roots development and planting suitability.

Precipitation condition is another important factor the erosion stability of the slope through the functions [3,14] such as raindrop impact, runoff erosion, rainfall infiltration, especially at the initial establishment stage of the protection system. Therefore, the main influencing factors are rainfall intensity, rainfall duration and rainfall capacity.

Besides, some objective condition such as construction technology, maintenance method and environmental condition also affect the erosion stability of the slope. Especially, the factors such as temperature, humidity and PH 
value cannot be ignored for the vegetation restoration.

In a word, whether the evaluation indexes are too many or too few may lead to error of the evaluation. Based on previous research, seven categories of the factors are considered in this study: (a) characteristics of 3D geomat; (b) characteristics of soil; (c) characteristics of slope; (d) characteristics of vegetation; (e) characteristics of rainfall; (f) construction and maintenance; $(\mathrm{g})$ environment. The factors and subfactors are as follows.

(a). The characteristics of $3 \mathrm{D}$ geomat: (1) layer number of the geomat $\mathrm{B}_{11}$; (2) thickness of the geomat $\mathrm{B}_{12}$; (3) material of geomat $\mathrm{B}_{13}$.

(b). The characteristics of soil: (1) cohesion of soil $\mathrm{B}_{21}$; (2) friction angle of soil $\mathrm{B}_{22}$; (3) bulk density of soil $\mathrm{B}_{23}$; (4) Permeability coefficient $\mathrm{B}_{24}$; (5) Degree of compaction $\mathrm{B}_{25}$; (6) pore pressure $\mathrm{B}_{26}$.

(c). The characteristics of slope: (1) slope angel $\mathrm{B}_{31}$; (2) slope length $\mathrm{B}_{32}$; (3) lithology $\mathrm{B}_{33}$

(d). The characteristics of vegetation: (1) vegetation coverage $\mathrm{B}_{41}$; (2) root development $\mathrm{B}_{42}$; (3) planting suitability $\mathrm{B}_{43}$.

(e). The characteristics of rainfall: (1) rainfall intensity $\mathrm{B}_{51}$; (2) rainfall duration $\mathrm{B}_{52}$; (3) rainfall capacity $\mathrm{B}_{53}$.

(f). Construction and maintenance: (1) construction technique $\mathrm{B}_{61}$; (2) maintenance way $\mathrm{B}_{62}$; (3) maintenance condition $\mathrm{B}_{63}$;

(g). Environment: (1) temperature $\mathrm{B}_{71}$; (2) humidity $\mathrm{B}_{72}$; (3) $\mathrm{PH}$ value $\mathrm{B}_{73}$.

Table 1. Classification of the influencing factors.

\begin{tabular}{|c|c|c|c|c|c|c|}
\hline \multirow{2}{*}{\multicolumn{2}{|c|}{ Evaluation index }} & \multicolumn{5}{|c|}{ Grade } \\
\hline & & grade I & gradeII & gradeIII & gradeIV & grade $V$ \\
\hline \multirow{3}{*}{ Characteristics of 3D geomat } & Thickness of the geomat $\mathrm{B}_{11}(\mathrm{~mm})$ & $>16$ & $14-16$ & $12-14$ & $10-12$ & $8-10$ \\
\hline & Tensile strength $\mathrm{B}_{12}(\mathrm{KN} / \mathrm{m})$ & $<1.0$ & $1.0-1.5$ & $1.5-2.0$ & $2.0-2.5$ & $>2.5$ \\
\hline & Soil Nails Spacing $B_{13}(\mathrm{~m})$ & $>3.2$ & $2.2-3.2$ & $1.5-2.2$ & $0.8-1.2$ & $<0.8$ \\
\hline \multirow{6}{*}{ The characteristics of soil } & Cohesion of soil $\mathrm{B}_{21}(\mathrm{kPa})$ & $>70.0$ & $50.0-70.0$ & $20.0-50.0$ & $10.0-20.0$ & $<10.0$ \\
\hline & Internal friction angle $\mathrm{B}_{22}\left({ }^{\circ}\right)$ & $>40.0$ & $30.0-40.0$ & $20.0-30.0$ & $10.0-20.0$ & $<10.0$ \\
\hline & Bulk density $B_{23}(\mathrm{KN} / \mathrm{m} 3)$ & $<12.0$ & $12.0-16.0$ & $16.0-20.0$ & $20.0-24.0$ & $>24.0$ \\
\hline & Permeability coefficient $\mathrm{B}_{24}(\mathrm{~cm} / \mathrm{s})$ & $10^{-8}-10^{-7}$ & $10^{-7}-10^{-6}$ & $10^{-6}-10^{-5}$ & $10^{-5}-10^{-4}$ & $10^{-4}-10^{-3}$ \\
\hline & Compactness $\mathrm{B}_{25}(\%)$ & $95-100$ & $90-95$ & $85-90$ & $80-85$ & $75-80$ \\
\hline & Ratio of pore pressure $B_{26}$ & $0.45-0.5$ & $0.4-0.45$ & $0.35-0.4$ & $0.3-0.35$ & $0.25-0.3$ \\
\hline \multirow{3}{*}{ The characteristics of slope } & Slope angel $\mathrm{B}_{31}\left({ }^{\circ}\right)$ & $<25$ & $25-45$ & $45-65$ & $65-75$ & $>75$ \\
\hline & Slope length $\mathrm{B}_{32}(\mathrm{~m})$ & $>50$ & $40-50$ & $25-40$ & $10-25$ & $<10$ \\
\hline & Lithology $B_{33}$ & very good & good & moderate & bad & very bad \\
\hline \multirow{3}{*}{ The characteristics of vegetation } & Vegetation coverage $\mathrm{B}_{41}(\%)$ & $>60$ & $45-60$ & $30-45$ & $10-30$ & $<10$ \\
\hline & Root development $\mathrm{B}_{42}$ & very good & good & moderate & bad & very bad \\
\hline & Planting suitability $\mathrm{B}_{43}$ & very good & good & moderate & poor & very poor \\
\hline \multirow{3}{*}{ The characteristics of rainfall } & Rainfall intensity $\mathrm{B}_{51}(\mathrm{~mm} / \mathrm{h})$ & $<0.4$ & $0.4-1.25$ & $1.25-5.8$ & $5.8-11.6$ & $>11.6$ \\
\hline & Rainfall duration $\mathrm{B}_{52}(\mathrm{~d})$ & $<1.0$ & $1.0-2.0$ & $3.0-5.0$ & $6.0-8.0$ & $>8.0$ \\
\hline & Daily rainfall capacity $\mathrm{B}_{53}(\mathrm{~d})$ & $<10.0$ & $10.0-30.0$ & $30.0-60.0$ & 60.0-140 & $>140.0$ \\
\hline \multirow{3}{*}{ Construction and maintenance } & Construction technique $\mathrm{B}_{61}$ & very good & good & moderate & bad & very bad \\
\hline & Maintenance condition $\mathrm{B}_{62}$ & very good & good & moderate & bad & very bad \\
\hline & Maintenance time $\mathrm{B}_{63}(\mathrm{~d})$ & $>60$ & $50-60$ & $40-50$ & $20-40$ & $<20$ \\
\hline \multirow{5}{*}{ Environment } & \multirow{2}{*}{ Temperature $\mathrm{B}_{71}\left({ }^{\circ} \mathrm{C}\right)$} & \multirow{2}{*}{$25.0-30.0$} & 20.0-25.0, & 10.0-20.0, & 0.0-10.0, & \multirow{2}{*}{ else } \\
\hline & & & $30.0-35.0$ & $35.0-40.0$ & $40.0-45.0$ & \\
\hline & Humidity $\mathrm{B}_{72}(\%)$ & $>60$ & $50-60$ & $40-50$ & $30-40$ & $<30$ \\
\hline & \multirow{2}{*}{ PH value $B_{73}$} & \multirow{2}{*}{ else } & $6.0-6.5$ & 5.5-6.0, & $5.0-5.5$ & \multirow{2}{*}{ else } \\
\hline & & & $7.5-8.0$ & $8.0-8.5$ & $8.5-9.0$ & \\
\hline
\end{tabular}

\subsection{Comprehensive Evaluation Grade}

The stability of slope is usually divided into five grades. Similarly, according to the stability of the slope, the erosion stability of the slope can also be divided into the following 5 grades: very stable (level I), stable (level II), basic 
stable (level III), unstable (level IV) and very unstable (level V). Besides, to maintain consistency with the evaluation grade, the evaluation index is divided into five grades, which is shown in the following Table 1.

\subsection{Comprehensive Evaluation Model}

Multiple-level comprehensive evaluation is a decision making technology that has been widely used for evaluation system with multiple factors and objectives. In this method, the evaluation index system is divided into a multiple-level structure, and the index weight of each layer is determined by AHP. The single index evaluation should be taken first and then the comprehensive evaluation is carried out to get the overall evaluation results by Calculating the single index evaluation result and its weight coefficient [16]. With the help of multilevel comprehensive evaluation, we can judge the erosion stability of the slope protected by the $3 \mathrm{D}$ geomat according to the following formula:

$$
\mathrm{B}=\mathrm{W} \circ \mathrm{R}
$$

In the formula, $\mathrm{W}$ means weight coefficient of all the evaluation indexes. $\mathrm{R}$ means the single index evaluation result matrix. B means the final evaluation result matrix of comprehensive evaluation.

In fact, the comprehensive evaluation index system of erosion stability of vegetated slope protected with 3D geomat is complex and uncertain. The system not only contains the fuzziness, but also contains the uncertainty such as the randomness and the discreteness, which the multiple-level comprehensive evaluation does not take into consideration. Therefore, to evaluate the erosion stability more comprehensively and objectively, the Qualitative Rule Generator based on Cloud Model is introduced into the comprehensive evaluation.

\section{COMPREHENSIVE EVALUATION BASED ON CLOUD MODEL}

\subsection{The Theory of Cloud Model [17]}

Cloud model, proposed by Academician Li Deyi in 1990s, is uncertainty conversion model between the qualitative concept and the quantitative data, which mainly reflects uncertainty in the objective world and knowledge: fuzziness and randomness [12]. The cloud model integrates the two characteristics and constitutes the mutual mapping between the qualitative concept and quantitative data.

Based on the probability theory and fuzzy mathematics, Cloud Model expresses a concept with three numeral characteristic [18]: Ex (expected value), En(entropy) and He(hyper entropy), which combine the fuzziness, randomness and discreteness organically and realizes the uncertainty conversion between qualitative knowledge and quantitative data. Ex (expected value)is the most representative value of the qualitative concept and reflects the central position the cloud model; En (entropy), the uncertainty measure of the qualitative concept, reflects the degree of discreteness of cloud droplets which represent the randomness and fuzziness of qualitative concept; He(hyper entropy), determined by randomness and uncertainty of entropy, is an uncertainty measure of entropy, which reveals the relationship between the fuzziness and randomness.

Definition 3.1: Suppose $\mathrm{U}$ is a quantitative theory which is expressed by a certain value and $\mathrm{C}$ is a qualitative concept on $\mathrm{U}$. If the quantitative value $\mathrm{x}$ is a random realization of the qualitative concept $\mathrm{C}$ and the certainty degree, $\mu$ $(x)$, of $\mathrm{x}$ is a random number with stable tendency for $\mathrm{C}$, which is to say:

$$
\mu: U \rightarrow[0,1] \quad \forall x \in U \quad x \rightarrow \mu(x)
$$

In this case, the distribution of $\mathrm{X}$ in the domain $\mathrm{U}$ is cloud. Each value of $\mathrm{x}$ is called a cloud droplet. Especially, if the number x satisfies $x=R_{N}\left(E_{x}, y\right)\left(R_{N}\right.$ means Gaussian distribution) while $y=R_{N}\left(E_{n}, H_{e}\right)$ and the certainty degree of $\mathrm{x}$ on $\mathrm{U}$ is $\mu(x)=\exp \left(-\frac{\left(x-E_{x}\right)}{2 y^{2}}\right)$, the cloud is called Normal Cloud Model. Normal Cloud Model is the most widely used cloud model and it has been proved to be generic [12]. The following picture show a cloud model that represents a qualitative concept (Fig. 1). 


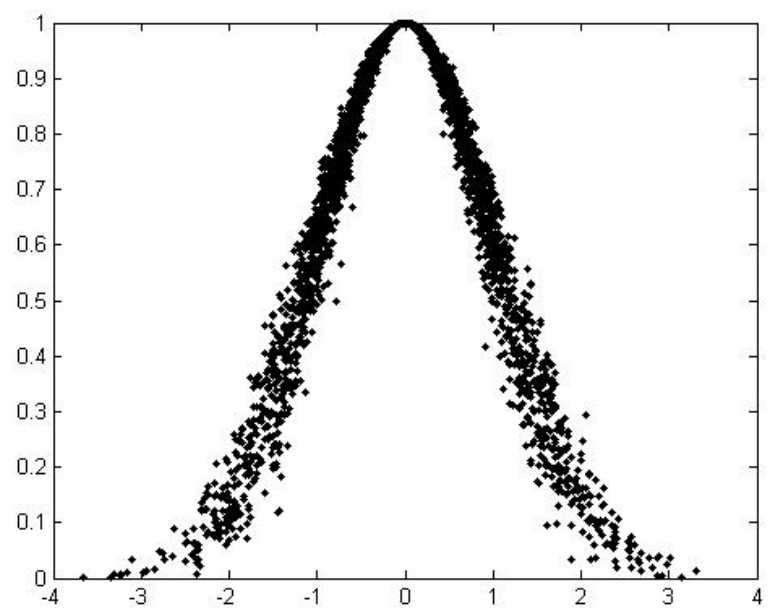

Fig. (1). Cloud model.

\subsection{Qualitative Rule Generator of Cloud Model [18]}

Definition 3.2: Forward Normal Cloud Generator (FCG) is a mapping from the qualitative concept to the quantitative data, which generates the cloud droplets according to the numerical characteristics (Ex, En, He).

Definition 3.3: Front Member Cloud Generator (FMCG) refers to the Forward Cloud Generator that generates membership degree distribution of a given point according to the point and numerical characteristics of cloud model.

Definition 3.4: Behind Member Cloud Generator (BMCG) refers to the Forward Cloud Generator that generates cloud droplet distribution according to the given membership degree and numerical characteristics of cloud model.

Definition 3.5: Backward Normal Cloud Generator (BCG) is a mapping from the quantitative to the qualitative, which converts a certain number of accurate data into a qualitative concept represented by numerical characteristics (Ex, En, He).

Definition 3.6: Qualitative Rule Generator (QRG), important application of Cloud Model theory, is consisted of Front Member Cloud Generator and Behind Member Cloud Generator to realize the uncertain conversion between the qualitative knowledge and quantitative data.

Qualitative Rule Generator based on Cloud Model may have multiple rules and multiple conditions. For the evaluation system of erosion stability, the article chooses the Qualitative Rule Generator with single condition and single rule. Its conceptual diagram and algorithm is shown in the following part (Fig. 2).

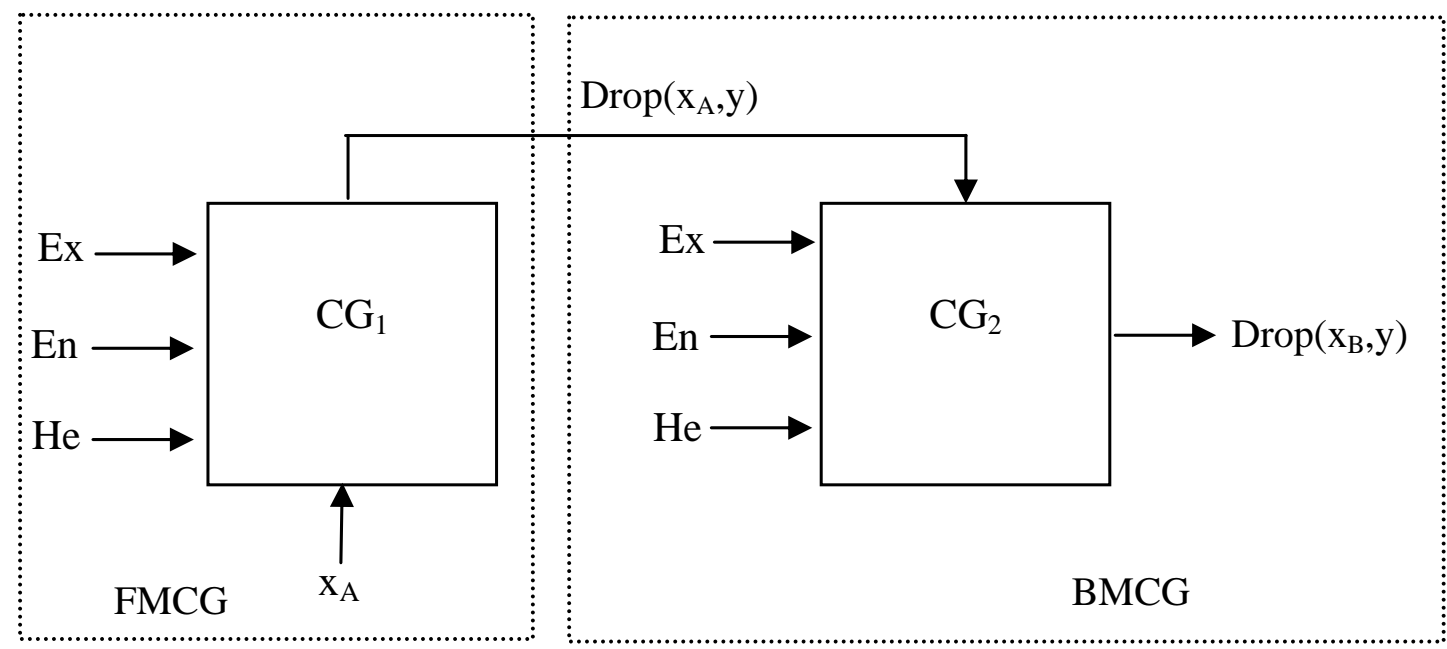

Fig. (2). Qualitative Rule Generator (single condition and single rule). 


\section{Algorithm 3.1}

Input: Three numeral characteristics $\left(E x_{A}, E n_{A} H e_{A}\right)$ of front member A and the quantitative value $x_{A}$, three numeral characteristics $\left(E x_{B}, E n_{B} H e_{B}\right)$ of behind member B.

Output: cloud droplet $x_{B}$ of behind member and its membership grade $\mu$.

(1) Generate a random number $E n_{A}^{\prime}$ that meets $\operatorname{Rn}\left(E n_{A}, H e_{A}\right)$;

(2) Calculate the membership grade $\mu$ :

$$
\mu=\exp \left(-\frac{\left(\mathrm{Xi}_{1}-E \mathrm{x}_{\mathrm{A}}^{\prime}\right)^{2}}{2 E \mathrm{x}^{\prime}{ }^{2}}\right)
$$

(3) Generate a random number $E n_{B}^{\prime}$ that meets $\operatorname{Rn}\left(E n_{B}, H e_{B}\right)$;

(4) If the inputted value activates the rising phase of the front member, the behind member choose the rising phase: If $x_{A} \leq E x_{A}$, then $\mathrm{X}_{\mathrm{B}}=E \mathrm{x}_{B}-E \mathrm{n}_{B}^{\prime} \times \sqrt{-2 \ln \mu}$;

(5) If the inputted value activates the decline phase of the front member, the behind member choose the decline phase: If $x_{A}>E x_{A}$, then $\mathrm{X}_{\mathrm{B}}=E \mathrm{x}_{B}+E \mathrm{n}_{B}^{\prime} \times \sqrt{-2 \ln \mu}$;

After the Cloud Model theory is applied into the erosion stability evaluation system, this study will take the uncertainty such as fuzziness and randomness of the evaluation system into consideration, making the result of the evaluation more objective and accurate.

\subsection{Improved AHP with Cloud Model [19]}

Analytic Hierarchy Process(AHP), put forward by American operation research scientist Satty.T.L [20], is a multiple criteria decision analysis method. It is flexible and can combine the qualitative and quantitative analysis. The traditional AHP use classical Satty scale (1-9) to describe the relative importance of different factors, and the weight of each index is calculated by constructing the comparison judgment matrix. However, using accurate number to express the relative importance may ignore the uncertainty of the relative importance. Besides, there may has randomness and fuzziness in the process of determining the relative importance value by the experts. Considering these factors, this study introduces the Cloud Model into the AHP by using the Backward Normal Cloud Generator to calculate the relative importance and optimize the the result of weight calculation .

$$
\begin{gathered}
E x=\frac{E x_{1}+E x_{2}+\cdots+E x_{n}}{n} \\
E n=\frac{\sqrt{\frac{\pi}{2} \sum_{i=1}^{n}\left|E x_{i}-E x\right|}}{n} \\
H e=\sqrt{\left|S^{2}-E n^{2}\right|}=\sqrt{\left|\frac{\sum_{i=1}^{n}\left(x_{i}-E x\right)^{2}}{n-1}-E n^{2}\right|} \mid
\end{gathered}
$$

(1) Invite $\mathrm{N}$ experts to judge the relative importance of the index. With the help of the Backward Normal Cloud Generator, we can generate a decision cloud about the judgment of experts.

(2) Build the judgment matrix of relative importance based on cloud model. First, the judgment matrix of relative importance is obtained according to group decision-making: 


$$
\left\{\begin{array}{cccc}
a_{11} & a_{12} & \ldots & a_{1 n} \\
a_{21} & a_{22} & \ldots & a_{2 n} \\
\ldots & \ldots & \ldots & \ldots \\
a_{n 1} & a_{n 2} & \ldots & a_{n n}
\end{array}\right\}=\left\{\begin{array}{cccc}
A_{11} E x_{11}, E n_{11}, H e_{11} & A_{12}\left(E x_{12}, E n_{12}, H e_{12}\right) & \ldots & A_{1 n}\left(E x_{1 n}, E n_{1 n}, H e_{1 n}\right) \\
A_{21}\left(E x_{21}, E n_{21}, H e_{21}\right) & A_{22}\left(E x_{22}, E n_{22}, H e_{22}\right) & \ldots & A_{2 n}\left(E x_{2 n}, E n_{2 n}, H e_{2 n}\right) \\
\ldots & \ldots & \ldots & \ldots \\
A_{n 1}\left(E x_{n 1}, E n_{n 1}, H e_{n 1}\right) & A_{n 2}\left(E x_{n 2}, E n_{n 2}, H e_{n 2}\right) & \ldots & A_{n n}\left(E X_{n n}, E n_{n n}, H e_{n n}\right)
\end{array}\right\}
$$

On the diagonal, the hyper entropy and the entropy of the cloud model is 0 and the expected value is $1 . A_{i j}$ is the reciprocal of $A_{i i}$, and according to the reciprocal algorithm of cloud model they satisfy the following formula:

$$
a_{j i}=A\left(E x_{j i}, E n_{j i}, H e_{j i}\right)=\frac{1}{a_{i j}}=\frac{1}{A\left(E x_{i j}, E n_{i j}, H e_{i j}\right)}=A\left(\frac{1}{E x}, \frac{E n}{(E x)^{2}}, \frac{H e}{(E x)^{2}}\right)
$$

(3) Calculate the relative weight coefficient of the evaluation elements according to root method: $W_{i}^{0}\left(E x_{i}^{0}, E n_{i}^{0}, H e_{i}^{0}\right)$. According to the multiplication of the cloud model, the calculation results of $W_{i}^{0}\left(E x_{i}^{0}, E n_{i}^{0}, H e_{i}^{0}\right)$ are listed as the following:

$$
\begin{gathered}
E x_{i}^{0}=\frac{E x_{i}}{\sum E x_{i}}=\frac{\left(\prod_{j=1}^{n} E x_{i j}\right)^{\frac{1}{n}}}{\sum_{i=1}^{n}\left(\prod_{j=1}^{n} E x_{i j}\right)^{\frac{1}{n}}} \\
E n_{i}^{0}=\frac{E n_{i}}{\sum_{E n_{i}}}=\frac{\left(\prod_{j=1}^{n} E x_{i j} \sqrt{\left.\sum_{j=1}^{n}\left(\frac{E n_{i j}}{E x_{i j}}\right)^{2}\right)^{\frac{1}{n}}}\right.}{\sum_{i=2}^{n}\left(\prod_{j=1}^{n} E x_{i j} \sqrt{\left.\sum_{j=1}^{n}\left(\frac{E n_{i j}}{E x_{i j}}\right)^{2}\right)^{\frac{1}{n}}}\right.} \\
H e_{i}^{0}=\frac{H e_{i}}{\sum H e_{i}}=\frac{\left(\prod_{j=1}^{n} E x_{i j} \sqrt{\sum_{j=1}^{n}\left(\frac{H e_{i j}}{E x_{i j}}\right)^{2}}\right)^{\frac{1}{n}}}{\sum_{i=2}^{n}\left(\prod_{j=1}^{n} E x_{i j} \sqrt{\sum_{j=1}^{n}\left(\frac{H e_{i j}}{E x_{i j}}\right)^{2}}\right)^{\frac{1}{n}}}
\end{gathered}
$$

(4) Take consistency test. The consistency test method for the three numerical characteristics of cloud model is consistent. Usually, we only take consistency test for the numerical characteristic Ex. The index of conformance test C.I. is 


$$
\text { C.I. }=\frac{\lambda_{\max }-n}{n-1}\left(\lambda_{\max } \approx \frac{1}{n} \sum_{i=1}^{n} \frac{\sum_{j=1}^{n} E X_{i j} W_{j}}{W_{j}}\right) .
$$

The index of consistency text is consistent with the classical AHP. C.R.,the proportion of conformance test, satisfies the following formula: C.R. $<0.1$.

\subsection{The Procedure of Comprehensive Evaluation}

(1) Classify the indexes of the comprehensive evaluation system according to the classification of comment set. Normalize [21] the variables with different dimensionless and predetermine the range of variation for the different grades.

For the influencing factor that the bigger the better, data normalization can be implemented as:

$$
\bar{b}_{i j}=\frac{b_{i j}-b_{j}^{\min }}{b_{j}^{\max }-b_{j}^{\min }}
$$

For the influencing factor that the smaller the better, data normalization can be implemented as:

$$
\bar{b}_{i j}=\frac{b_{j}^{\max }-b_{i j}}{b_{j}^{\max }-b_{j}^{\min }}
$$

(2) Format the cloud model of the comments set. According to the range of the comments set and the definition of the score of comments set, the three numerical characteristics of the cloud model are determined [22].

a) As mentioned above, $E_{X}$ is the expected value of sample points that meet normal distribution, therefore,

$$
E x_{i, j}=\left(x_{i, j}^{1}+x_{i, j}^{2}\right) \div 2
$$

In the formula, $E x_{i, j}$ means the expected value of factor ' $\mathrm{i}$ ' of grade ' $\mathrm{j}$ '. $x_{i, j}^{1}$ means the maximum value and $x_{i, j}^{2}$ means minimum value in the section of different grades.

b) In order to show the boundary fuzziness of adjacent grades, the membership of the two adjacent grades is equal. Therefore, the En (entropy)is determined by the following equation:

$$
\begin{gathered}
\exp \left[-\frac{\left(x_{i, j}^{1}-x_{i, j}^{2}\right)^{2}}{8\left(E n_{i, j}\right)^{2}}\right] \approx 0.5 \\
E n_{i, j}=\frac{x_{i, j}^{1}-x_{i, j}^{2}}{2.355}
\end{gathered}
$$

c) The He(hyper entropy)is usually determined by experience. The value of He(hyper entropy) is usually less than 0.05 . The paper make the value as $H e=0.01$.

(3) Evaluate the single factor of the evaluation system by qualitative rules generator based on cloud model according to the uncertain reasoning method.

(4) Determine the weight coefficient of the index of the evaluation system. The article selects AHP improved with Cloud Model, considering the fuzziness and randomness of the subjective factors in the evaluation process.

(5) Calculate the score of each evaluation index with its weight coefficient, then we can obtain the final score of the 
comprehensive evaluation, further we can obtain the evaluation grade of the erosion stability.

\section{THE ANALYSIS OF ENGINEERING CASE}

Qinghong expressway is located in the east Shandong Province. The speed limit of the expressway is $120 \mathrm{~km} / \mathrm{h}$ and the width of the roadbed is $34.5 \mathrm{~m}$. The design slope angel is $40^{\circ}$ and the design length of the slope is $15 \mathrm{~m}$. Geomat protection of slope has been used to protect the erosion stability of the slope. To evaluate the erosion stability, the comprehensive evaluation based on Cloud Model is applied and the Table 2 shows the relative data of Qinghong Expressway and its normalization.

Table 2. Relative Data and its normalization of Qinghong Expressway.

\begin{tabular}{|c|c|c|c|c|c|}
\hline Evaluation factor & Original & Normalization & Evaluation factor & Original & Normalization \\
\hline \multirow{12}{*}{$\begin{array}{c}\text { Thickness }(\mathrm{mm}) \\
\text { Tensile strength }(\mathrm{KN} / \mathrm{m}) \\
\text { Soil Nails Spacing }(\mathrm{m}) \\
\text { Cohesion of soil }(\mathrm{kPa}) \\
\text { Internal friction angle }\left({ }^{\circ}\right) \\
\text { Bulk density }(\mathrm{KN} / \mathrm{m} 3) \\
\text { Permeability coefficient }(\mathrm{cm} / \mathrm{s}) \\
\text { Compactness }(\%) \\
\text { Ratio of pore pressure } \\
\text { Slope angel }\left(^{\circ}\right) \\
\text { Slope length }(\mathrm{m}) \\
\text { Lithology }\end{array}$} & $14 \mathrm{~mm}$ & 0.75 & \multirow{12}{*}{$\begin{array}{c}\text { Vegetation coverage }(\%) \\
\text { Root development } \\
\text { Planting suitability } \\
\text { Rainfall intensity }(\mathrm{mm} / \mathrm{h}) \\
\text { Rainfall duration }(\mathrm{d}) \\
\text { Daily rainfall capacity }(\mathrm{mm}) \\
\text { Construction technique } \\
\text { Maintenance condition } \\
\text { Maintenance time }(\mathrm{d}) \\
\text { Temperature }\left({ }^{\circ} \mathrm{C}\right) \\
\text { Humidity }(\%) \\
\text { PH value }\end{array}$} & $40 \%$ & 0.59 \\
\hline & $2 \mathrm{KN} / \mathrm{m}$ & 0.5 & & good & 0.7 \\
\hline & $1 \mathrm{~m}$ & 0.95 & & good & 0.7 \\
\hline & $62.92 \mathrm{kPa}$ & 0.899 & & $2.5 \mathrm{~mm} / \mathrm{h}$ & 0.78 \\
\hline & $23.09^{\circ}$ & 0.577 & & 0.5 day & 0.938 \\
\hline & $18.7 \mathrm{KN} / \mathrm{m}^{3}$ & 0.221 & & $5 \mathrm{~mm}$ & 0.964 \\
\hline & $3.2 \times 10^{-6} \mathrm{~cm} / \mathrm{s}$ & 0.72 & & good & 0.7 \\
\hline & $90 \%$ & 0.8 & & moderate & 0.5 \\
\hline & 0.3 & 0.2 & & 45 day & 0.5 \\
\hline & $40^{\circ}$ & 0.66 & & $16^{\circ} \mathrm{C}$ & 0.533 \\
\hline & $15 \mathrm{~m}$ & 0.17 & & $50 \%$ & 0.833 \\
\hline & poor & 0.3 & & 8.4 & 0.35 \\
\hline
\end{tabular}

Table 3. The classification and the normalization of the evaluation index.

\begin{tabular}{|c|c|c|c|c|c|c|}
\hline \multirow{2}{*}{\multicolumn{2}{|c|}{ Evaluation index }} & \multicolumn{5}{|c|}{ Grade } \\
\hline & & \multirow{2}{*}{\begin{tabular}{|c|} 
grade $\mathbf{I}$ \\
$0.95-1$ \\
$0.95-1$ \\
$0.95-1$ \\
\end{tabular}} & \multirow{2}{*}{\begin{tabular}{|c|} 
gradeII \\
$0.75-0.95$ \\
$0.65-0.95$ \\
$0.65-0.95$ \\
\end{tabular}} & \multirow{2}{*}{\begin{tabular}{|c|} 
gradeIII \\
$0.5-0.75$ \\
$0.35-0.65$ \\
$0.35-0.65$ \\
\end{tabular}} & \multirow{2}{*}{\begin{tabular}{|c|} 
gradeIV \\
$0.25-0.5$ \\
$0.05-0.35$ \\
$0.05-0.35$ \\
\end{tabular}} & \multirow{2}{*}{\begin{tabular}{|c|} 
grade V \\
$0-0.25$ \\
$0-0.05$ \\
$0-0.05$ \\
\end{tabular}} \\
\hline characteristics of $3 \mathrm{D}$ geomat & $\begin{array}{c}\text { Thickness of the geomat } \mathrm{B}_{11}(\mathrm{~mm}) \\
\text { Tensile strength } \mathrm{B}_{12}(\mathrm{KN} / \mathrm{m}) \\
\text { Soil Nails Spacing } \mathrm{B}_{13}(\mathrm{~m})\end{array}$ & & & & & \\
\hline The characteristics of soil & $\begin{array}{c}\text { Cohesion of soil } \mathrm{B}_{21}(\mathrm{kPa}) \\
\text { Internal friction angle } \mathrm{B}_{22}\left({ }^{\circ}\right) \\
\text { Bulk density } \mathrm{B}_{23}(\mathrm{KN} / \mathrm{m} 3) \\
\text { Permeability coefficient } \mathrm{B}_{24}(\mathrm{~cm} / \mathrm{s}) \\
\text { Compactness } \mathrm{B}_{25}(\%) \\
\text { Ratio of pore pressure } \mathrm{B}_{26}\end{array}$ & $\begin{array}{c}0.875-1 \\
0.8-1 \\
0.95-1 \\
0.95-1 \\
0.8-1 \\
0.8-1\end{array}$ & $\begin{array}{c}0.625-0.875 \\
0.6-0.8 \\
0.65-0.95 \\
0.65-0.95 \\
0.6-0.8 \\
0.6-0.8\end{array}$ & \begin{tabular}{|}
$0.25-0.625$ \\
$0.4-0.6$ \\
$0.35-0.65$ \\
$0.35-0.65$ \\
$0.4-0.6$ \\
$0.4-0.6$
\end{tabular} & $\begin{array}{c}0.125-0.25 \\
0.2-0.4 \\
0.05-0.35 \\
0.05-0.35 \\
0.2-0.4 \\
0.2-0.4\end{array}$ & $\begin{array}{c}0-0.125 \\
0-0.2 \\
0-0.05 \\
0-0.05 \\
0-0.2 \\
0-0.2\end{array}$ \\
\hline The characteristics of slope & $\begin{array}{c}\text { Slope angel } B_{31}\left({ }^{\circ}\right) \\
\text { Slope length } B_{32}(\mathrm{~m}) \\
\text { Lithology } B_{33}\end{array}$ & $\begin{array}{l}0.9-1 \\
0.9-1 \\
0.8-1\end{array}$ & $\begin{array}{c}0.58-0.9 \\
0.7-0.9 \\
0.6-0.8 \\
\end{array}$ & $\begin{array}{c}0.26-0.58 \\
0.4-0.7 \\
0.4-0.6 \\
\end{array}$ & $\begin{array}{c}0.1-0.26 \\
0.1-0.4 \\
0.2-0.4 \\
\end{array}$ & $\begin{array}{l}0-0.1 \\
0-0.1 \\
0-0.2\end{array}$ \\
\hline The characteristics of vegetation & $\begin{array}{c}\text { Vegetation coverage } \mathrm{B}_{41}(\%) \\
\text { Root development } \mathrm{B}_{42} \\
\text { Planting suitability } \mathrm{B}_{43}\end{array}$ & \begin{tabular}{c|}
$0.95-1$ \\
$0.8-1$ \\
$0.8-1$
\end{tabular} & $\begin{array}{c}0.65-0.95 \\
0.6-0.8 \\
0.6-0.8\end{array}$ & \begin{tabular}{|c|}
$0.35-0.65$ \\
$0.4-0.6$ \\
$0.4-0.6$
\end{tabular} & \begin{tabular}{|c|}
$0.05-0.35$ \\
$0.2-0.4$ \\
$0.2-0.4$ \\
\end{tabular} & $\begin{array}{c}0-0.05 \\
0-0.2 \\
0-0.2\end{array}$ \\
\hline The characteristics of rainfall & $\begin{array}{l}\text { Rainfall intensity } \mathrm{B}_{51}(\mathrm{~mm} / \mathrm{h}) \\
\text { Rainfall duration } \mathrm{B}_{52}(\mathrm{~d}) \\
\text { Daily rainfall capacity } \mathrm{B}_{53}(\mathrm{~d})\end{array}$ & \begin{tabular}{|l|}
$0.95-1$ \\
$0.95-1$ \\
$0.95-1$ \\
\end{tabular} & \begin{tabular}{|c|}
$0.9-0.95$ \\
$0.82-0.95$ \\
$0.81-0.0 .95$ \\
\end{tabular} & \begin{tabular}{|c|}
$0.5-0.9$ \\
$0.44-0.82$ \\
$0.6-0.81$ \\
\end{tabular} & \begin{tabular}{|c|}
$0.05-0.5$ \\
$0.05-0.44$ \\
$0.05--0.6$ \\
\end{tabular} & $\begin{array}{l}0-0.05 \\
0-0.05 \\
0-0.05 \\
\end{array}$ \\
\hline Construction and maintenance & $\begin{array}{l}\text { Construction technique } \mathrm{B}_{61} \\
\text { Maintenance condition } \mathrm{B}_{62} \\
\text { Maintenance time } \mathrm{B}_{63}(\mathrm{~d})\end{array}$ & \begin{tabular}{c|}
$0.8-1$ \\
$0.8-1$ \\
$0.95-1$
\end{tabular} & $\begin{array}{c}0.6-0.8 \\
0.6-0.8 \\
0.65-0.95\end{array}$ & \begin{tabular}{|c|}
$0.4-0.6$ \\
$0.4-0.6$ \\
$0.35-0.65$
\end{tabular} & \begin{tabular}{|c|}
$0.2-0.4$ \\
$0.2-0.4$ \\
$0.05-0.35$ \\
\end{tabular} & $\begin{array}{c}0-0.2 \\
0-0.2 \\
0-0.05\end{array}$ \\
\hline Environment & $\begin{array}{c}\text { Temperature } \mathrm{B}_{71}\left({ }^{\circ} \mathrm{C}\right) \\
\text { Humidity } \mathrm{B}_{72}(\%) \\
\text { PH value } \mathrm{B}_{73}\end{array}$ & \begin{tabular}{c|}
$0.8-1$ \\
$0.95-1$ \\
$0.8-1$
\end{tabular} & \begin{tabular}{|c|}
$0.6-0.8$ \\
$0.65-0.95$ \\
$0.6-0.8$
\end{tabular} & \begin{tabular}{|c|}
$0.4-0.6$ \\
$0.35-0.65$ \\
$0.4-0.6$
\end{tabular} & \begin{tabular}{|c|}
$0.2-0.4$ \\
$0.05-0.35$ \\
$0.2-0.4$ \\
\end{tabular} & $\begin{array}{c}0-0.2 \\
0-0.05 \\
0-0.2\end{array}$ \\
\hline
\end{tabular}

\subsection{The Classification and the Normalization of the Evaluation Index}

In this paper, the erosion stability of the slope protected by 3D geomat is divided into 5 grades: Very stable (grade I), stable (gradeII), basically stable (gradeIII), unstable (gradeIV), very unstable (grade V). In order to keep the 
consistency of the forward cloud model and backward cloud model, classify the evaluation index into 5 grades and normalize the date of the evaluation index. The result of the classification and normalization is given in the Table $\mathbf{3}$.

\subsection{Build the Front Member Cloud Model and Behind Member Cloud Model}

According to the variation range of the classification for each index and the formula (3-9) (3-12), the front member cloud model is developed. For example, for the index 'the thickness of $3 \mathrm{D}$ geomat', the cloud model $\left(\mathrm{E}_{\mathrm{x}}, \mathrm{E}_{\mathrm{n}}, \mathrm{H}_{\mathrm{e}}\right)$ are: $(0.975,0.05 / 2.355,0.01),(0.8,0.3 / 2.355,0.01),(0.5,0.3 / 2.355,0.01),(0.2,0.3 / 2.355,0.01),(0.025,0.05 / 2.355$, $0.01)$ corresponding to its qualitative comment 'very stable, stable, generally stable, unstable and very unstable'.

For the behind member cloud model, assuming that the better the index is, the higher the score is. If the full mark is 100, the cloud model are: $(90,20 / 2.355,0.01),(70,20 / 2.355,0.01),(50,20 / 2.355,0.01),(30,20 / 2.355,0.01),(10$, $20 / 2.355,0.01)[23]$ corresponding to its qualitative comment 'very high, high, medium, low and very low'.

\subsection{Determine Weight Coefficient}

The study uses AHP developed with Cloud Model (CM-AHP) to calculate the weight coefficient of the evaluation index to make the calculation results more objective. The calculation procedure is shown in the chapter 3.3. The article take the index $\mathrm{B}_{1}$ "the characteristics of the $3 \mathrm{D}$ geomat " as an example to show the calculation procedure, the result is given in the Table 4. And the calculation results of the weights of all indexes are given in the Table 5.

Table 4. Judgement matrix.

\begin{tabular}{|c|c|c|c|}
\hline $\mathbf{B}$ & $\mathbf{B}_{11} \mathbf{B}_{12} \mathbf{B}_{13}$ & $\bar{W}_{i}$ & $W_{i}^{0}$ \\
\hline $\mathrm{B}_{11}$ & $(1,0,0)(4,0.836,0.050)(0.260,0.054,0.011)$ & $(1.013,0.674,0.358)$ & $(0.234,0.246,0.234)$ \\
$\mathrm{B}_{11}$ & $(0.25,0.053,0.003)(1,0,0)(0.145,0.018,0.003)$ & $(0.331,0.207,0.095)$ & $(0.077,0.076,0.062)$ \\
$\mathrm{B}_{13}$ & $(3.846,0.799,0.163)(6.897,0.856,0.143)(1,0,0)$ & $(2.982,1.858,1.078)$ & $(0.689,0.678,0.704)$ \\
\hline
\end{tabular}

Conformance Test: C.I. $=0.035$, R.I. $=0.52$, C.R $=0.067<0.1$

Table 5. Weight coefficient and score of evaluation index.

\begin{tabular}{|c|c|c|c|c|c|c|}
\hline Score & $1^{\text {st }}$ index & Weight & Score & $2^{\text {nd }}$ index & Weight & Score \\
\hline \multirow{7}{*}{58.921} & characteristics of $3 \mathrm{D}$ geomat & 0.217 & 72.760 & $\begin{array}{c}\text { Soil Nails Spacing }(\mathrm{m}) \\
\text { Thickness of the geomat }(\mathrm{mm}) \\
\text { Tensile strength of geomat }(\mathrm{KN} / \mathrm{m})\end{array}$ & $\begin{array}{l}0.234 \\
0.077 \\
0.689\end{array}$ & $\begin{array}{l}60.358 \\
50.000 \\
79.515\end{array}$ \\
\hline & The characteristics of soil & 0.147 & 47.953 & $\begin{array}{c}\text { Cohesion of soil }(\mathrm{kPa}) \\
\text { Internal friction angle }\left(^{\circ}\right) \\
\text { Bulk density }(\mathrm{KN} / \mathrm{m} 3) \\
\text { Permeability coefficient }(\mathrm{cm} / \mathrm{s}) \\
\text { Compactness }(\%) \\
\text { Ratio of pore pressure }\end{array}$ & $\begin{array}{l}0.100 \\
0.039 \\
0.458 \\
0.312 \\
0.056 \\
0.035\end{array}$ & $\begin{array}{l}62.805 \\
46.567 \\
31.585 \\
64.472 \\
80.875 \\
21.318\end{array}$ \\
\hline & The characteristics of slope & 0.353 & 48.653 & $\begin{array}{c}\text { Slope angel }\left({ }^{\circ}\right) \\
\text { Slope length }(\mathrm{m}) \\
\text { Lithology }\end{array}$ & $\begin{array}{l}0.578 \\
0.309 \\
0.113\end{array}$ & $\begin{array}{l}65.413 \\
24.125 \\
30.000\end{array}$ \\
\hline & The characteristics of vegetation & 0.138 & 64.332 & $\begin{array}{c}\text { Vegetation coverage }(\%) \\
\text { Root development } \\
\text { Planting suitability }\end{array}$ & $\begin{array}{l}0.392 \\
0.406 \\
0.202 \\
\end{array}$ & $\begin{array}{l}55.410 \\
70.000 \\
70.254 \\
\end{array}$ \\
\hline & The characteristics of rainfall & 0.078 & 77.100 & $\begin{array}{l}\text { Rainfall intensity }(\mathrm{mm} / \mathrm{h}) \\
\text { Rainfall duration }(\mathrm{d}) \\
\text { Daily rainfall capacity }(\mathrm{d})\end{array}$ & $\begin{array}{l}0.582 \\
0.256 \\
0.162\end{array}$ & $\begin{array}{l}73.877 \\
78.882 \\
85.862\end{array}$ \\
\hline & Construction and maintenance & 0.048 & 61.440 & $\begin{array}{l}\text { Construction technique } \\
\text { Maintenance condition } \\
\text { Maintenance time (d) }\end{array}$ & $\begin{array}{l}0.572 \\
0.286 \\
0.142\end{array}$ & $\begin{array}{l}70.000 \\
50.000 \\
50.000\end{array}$ \\
\hline & Environment & 0.019 & 56.177 & $\begin{array}{c}\text { Temperature }\left({ }^{\circ} \mathrm{C}\right) \\
\text { Humidity }(\%) \\
\text { PH value }\end{array}$ & $\begin{array}{l}0.324 \\
0.126 \\
0.550\end{array}$ & $\begin{array}{l}51.198 \\
71.198 \\
55.669\end{array}$ \\
\hline
\end{tabular}

\subsection{Single Factor Evaluation}

According to the uncertainty reasoning based on cloud model, the qualitative language description of evaluation index is quantified as the certain score with the help of Qualitative Rule Generator based on cloud model. The calculation results are provided in the Table $\mathbf{5}$. 


\subsection{The Comprehensive Evaluation}

Multiply the score of the evaluation index with the weight coefficient to get comprehensive evaluation score. The score of comprehensive evaluation based on cloud model is 58.921 and the grade of the erosion stability is grade III. To prove the feasibility of the cloud model in comprehensive evaluation, we use the fuzzy matter-element [24] to evaluate the same example. The result shows consistent with the result of the comprehensive evaluation using cloud model.

\section{CONCLUSION}

With the increasing number of slope engineering, the traditional slope protection technology is no longer able to meet the requirements no matter on economics or environment. As a kind of new technology, ecological slope protection technology is beneficial to environmental protection. It will not only protect slope stability and prevent erosion, but also will combine the slope engineering with the surrounding ecological landscape which is environmentally friendly. The analysis of erosion stability of vegetated eco-slope protected by $3 \mathrm{D}$ geomat is the basic work of the design of the engineering. There are many factors that affect the erosion stability of slope. Besides, the randomness and fuzziness of these factors increase the uncertainty of the evaluation. In this paper, the Cloud Model is applied into the comprehensive evaluation of the erosion stability of vegetated eco-slope protected by 3D geomat. With the help of MATLAB [25] program, the article builds a qualitative rule generator based on cloud model to realize the conversion between the qualitative concept and the quantitative data. Through the analysis of engineering case, the evaluation method is proved to be feasible and easy to be calculated, which provides a new method for the analysis of the erosion stability of the vegetated slope by 3D geomat. Compared with the traditional evaluation method, on one hand the new method will no longer consider membership functions and on the other hand it considers the fuzziness and randomness of the evaluation process fully by introducing the Cloud Model. The Cloud Model optimize the theoretical system of the research on the erosion stability of the vegetated eco-slope protected by the 3D geomat and has important guiding significance to practical engineering.

\section{CONFLICT OF INTEREST}

The authors confirm that this article content has no conflict of interest.

\section{ACKNOWLEDGEMENTS}

The supports given to this work by the National Natural Science Foundation of China (No. 11372165) are greatly acknowledged.

\section{REFERENCES}

[1] C.G. Bao, Principle and Application of Geosynthetics in Engineering., China Water \& Power Press: Beijing, 2008.

[2] X.L. Lin, Q. Gao, and H.L. Xiao, "Slope protection technology of grass seeding based on 3D geomat", Journal of Yangtze River Scientific Research Institute., vol. 25, pp. 58-61, 2008.

[3] Z. J. Zheng, and Z. D. Shi, "Shallow layer stability analysis of ecological slope considering vegetation factor", Urban Roads Bridges \& Flood Control., vol. 114, pp. 105-107, 2014.

[4] J.W. Huang, J.L. Li, and Y.H. Zhou, "Application of fuzzy analysis based on AHP to slope stability evaluation", Chinese Journal of Rock Mechanics and Engineering., vol. 26, no. 1, pp. 2627-2632, 2007.

[5] Z.J. Wang, "Analysis and application of soil slope stability based on grey theory", M.S. Thesis, Southwest Jiaotong University, Chengdu, ON, China, 2011.

[6] D.Z. Jiang, C.F. Peng, and L. Liu, "Forecasting soil slope stability with MEP algorithm", Journal of Shantou University, vol. 26, pp. 66-72, 2011. [Natural Science Edition].

[7] G.S. Su, "Fast estimation of safety for circular failure rock slope using Gaussian process model", Journal of Basic Science and Engineering, vol. 18, pp. 959-966, 2010.

[8] N. Zhou, H.L. Fu, and Y. Yuan, "Evaluation approach of slope stability based on fuzzy neural network", Chinese Journal of underground space and Engineering., vol. 5, pp. 1826-1832, 2009.

[9] M.A. Navacerrada, and A. Pedrero, "C. DÃaz, Study of the uncertainty of faÃßade sound insulation measurements: Analysis of the ISO 12999-1 uncertainty proposal", Applied Acoustics, vol. 114, pp. 1-9, 2016. [http://dx.doi.org/10.1016/j.apacoust.2016.03.033]

[10] X. X. Zhang, G. T. Wang, and M. Zhang, "Application of PPE model based on accelerating genetic algorithm in the evaluation of slope stability", Journal of Hefei University of Technology(Nature Science)., vol. 31, no. 3, pp. 430-432, 2008. 
[11] G.Y. Wang, C.L. Xu, and D.Y. Li, "Generic normal cloud model", Information Science, vol. 280, pp. 1-15, 2014. [http://dx.doi.org/10.1016/j.ins.2014.04.051]

[12] G.Y. Wang, H.L. Cui, and Q. Li, "Investigation of method for determining factors weights in evaluating slope stability based on rough set theory", Rock and Soil Mechanics, vol. 30, no. 8, pp. 2418-2422, 2009.

[13] G.Y. Wang, J.P. Zhang, and T.Y. Xu, "Numerical analysis of geocell protective slope stability", Applied Mechanics and Materials, vol. 353, pp. 635-639, 2013.

[14] H.L. Xiao, Z. Wang, and J.F. Zhang, "Study on the design indexes of three dimensional geomat", Rock and Soil Mechanics, vol. 25, pp. 1800-1804, 2004.

[15] J.X. Wei, "Research on the Stability of 3D-geomat Protection of Slope", M.S. Thesis, Shandong University, Ji'nan, ON, China, 2013.

[16] G.Y. Wang, Comprehensive Evaluation Technology and Application to Civil Engineering., China Water \& Power Press: Beijing, 2011.

[17] G.R. Wang, D.Y. Li, and Y.Y. Yao, Cloud Model and Granular Computing., Science Press: Beijing, 2011.

[18] D.Y. Li, and Y. Du, Artificial Intelligence of Uncertainty., National Defend Industry Press: Beijing, 2005.

[19] H.L. Wang, and Y.Q. Feng, "Improved AHP based on judgment matrix scaled with cloud model", Chinese Journal of Management Science, vol. 13, pp. 31-37, 2005.

[20] T.L. Saaty, The Analytical Hierarchy Process, New Nork., McGraw-Hill, 1980.

[21] G.L. Liang, W.Y. Xu, and X.L. Tan, "Application of extension theory based on entropy weight to rock quality evaluation", Rock and Soil Mechanics, vol. 31, pp. 535-540, 2010.

[22] Y.S. Cao, X, N, Chen, and W. Zhang, "Application of evaluation model based on cloud theory in water resources carrying capacity", Journal of North China Institute of Water Conservancy and Hydroelectric Power, vol. 31, pp. 17-20, 2010.

[23] Q.Y. Shuai, and Y.B. He, "Comprehensive evaluation on rock quality of dam foundation based on cloud model", Journal of Southeast University, vol. 43, no. z1, pp. 54-58, 2013. [Natural Science Edition].

[24] G.Y. Wang, and J.W. Zhao, "The fuzzy matter-element comprehensive evaluation model for erosion stability of geocell protection of slope and its application", Advances in Industrial and Civil Engineering, vol. 594-597, pp. 2945-2950, 2012.

[25] M. Michel, M. Yves, and P. Jean-Michel, Wavelet Toolbox TM 4, User's Guide., The MathWorks. Inc, 2009.

(C) Guangyue et al.; Licensee Bentham Open

This is an open access article licensed under the terms of the Creative Commons Attribution-Non-Commercial 4.0 International Public License (CC BY-NC 4.0) (https://creativecommons.org/licenses/by-nc/4.0/legalcode), which permits unrestricted, non-commercial use, distribution and reproduction in any medium, provided the work is properly cited. 